\title{
Neutrophil/lymphocyte ratio in patients with atrial septal aneurysm
}

This article was published in the following Dove Press journal:

Vascular Health and Risk Management

18 July 2013

Number of times this article has been viewed

\section{Mehmet Demir' \\ Canan Demir ${ }^{2}$ \\ 'Department of Cardiology, Bursa Yüksek Ihtisas Education and Research Hospital, Bursa, Turkey; ${ }^{2}$ Department of Infectious Diseases, Bursa Șevket Yılmaz Education and Research Hospital, Bursa, Turkey}

Correspondence: Mehmet Demir Yaseminpark sit, 4-E blok D:II Osmangazi 16100, Bursa, Turkey Tel +902242573328 Email drmehmetmd@gmail.com
Background: Systemic thromboembolism is a serious, major complication in patients with an atrial septal aneurysm (ASA). Paroxysmal atrial fibrillation (AF) is more common in patients with ASA than in the normal population. Neutrophil/lymphocyte ratio (NLR) has been associated with postoperative AF development in patients who have undergone cardiac surgery. This study investigated NLR in a group of ASA patients compared with a control group of healthy volunteers.

Patients and methods: The study group consisted of 40 patients with ASA; the control group consisted of 30 age-, sex-, and body mass index-matched healthy volunteers. All patients and control subjects underwent echocardiographic examination. No patient had a recent history of an acute infection or an inflammatory disease. Baseline NLR was measured by dividing neutrophil count by lymphocyte count.

Results: No statistically significant difference was found between the two groups in terms of basic characteristics. Mean NLR was significantly higher among persons with ASA compared with controls $(3.4 \pm 1.5$ vs $1.6 \pm 0.97, P<0.001)$.

Conclusion: Our results suggest that a higher NLR, an emerging marker of inflammation, has a positive correlation with ASA. The measurement of NLR may be used to indicate an increased risk of arrhythmia, such as AF, in ASA patients.

Keywords: neutrophil-lymphocyte ratio, inflammation, arrhythmia

\section{Introduction}

Atrial septal aneurysm (ASA) is a risk factor for arterial embolism because it frequently coexists with an atrial septal defect or patent foramen ovale and mitral valve prolapse. The incidence of ASA, depending on the imaging method, is reported to be $0.2 \%-4 \%$ with transthoracic echocardiography and $2 \%-8 \%$ with transesophageal echocardiography because of higher sensitivity. ${ }^{1-3}$

It was recently demonstrated that atrial dysfunction caused by paroxysmal atrial fibrillation (AF) is more common in patients with ASA than in the normal population, although the mechanisms of this dysfunction remain unclear. ${ }^{4}$

Elevated levels of systemic inflammatory markers have been found to be associated with incidences of cardiovascular diseases such as coronary artery disease, hypertension, and AF. ${ }^{5-7}$ Total white blood cell (WBC) count and subtypes, such as neutrophil, lymphocyte, and neutrophil/lymphocyte ratio (NLR), can be used as indicators of systemic inflammation. ${ }^{8}$

In our study, we compared NLR between ASA patients and controls. submit your manuscript | www.dovepress.com

Dovepress

http://dx.doi.org// 0.2147/VHRM.S48778
Vascular Health and Risk Management 2013:9 365-368

(C) 2013 Demir and Demir, publisher and licensee Dove Medical Press Ltd. This is an Open Access article which permits unrestricted noncommercial use, provided the original work is properly cited. 


\section{Methods}

\section{Patient selection}

Forty patients with ASA who had been identified during echocardiographic evaluation, performed for various reasons (15 males, 25 females; mean [ \pm standard deviation] age $54.4 \pm 16.3$ years), were entered into the present study. Thirty age-matched adults (12 males, 18 females; mean age $49.8 \pm 11.2$ years) who had normal cardiac structures on echocardiography comprised the control group. Entry criteria included the presence of ASA determined by echocardiography and sinus rhythm on surface electrocardiogram. A physical examination, medical history, and blood biochemistry testing were conducted in both patient groups. The subjects were defined as hypertensive if their blood pressure was $\geq 140 / 90 \mathrm{mmHg}$ or if they were receiving any antihypertensive medication. Diabetes mellitus was defined as a history of antidiabetic medication use or a fasting glucose level $>126 \mathrm{mg} / \mathrm{dL}$. Smoking status was classified as smokers and those who had never smoked. Patients with coronary artery disease, heart failure, valve disease, cardiomyopathy, hypertension, diabetes mellitus, chronic lung disease, thyroid dysfunction, anemia, malignancy, renal and hepatic insufficiency, chronic inflammatory disease, pregnancy, septicemia, hematological disorders, known malignancy, WBC count $>12,000$ cells per $\mu \mathrm{L}$ or $<4000$ cells per $\mu \mathrm{L}$, and high body temperature $>38^{\circ}$ were excluded from the study. Also, patients who had a recent history of an acute infection or an inflammatory disease or had a history of stroke or cerebrovascular disorder were excluded from the study. All patients in the present study were in sinus rhythm, and none were taking cardioactive medications such as antiarrhythmics, antiplatelets, anticoagulants, antipsychotics, or antihistamines. Patients who had taken medication that can potentially interfere with the measurement of leukocyte counts, such as antigout or antiinflammatory agents, were excluded from study.

\section{Echocardiographic measurements}

Two-dimensional, M-mode, pulsed, and color-flow Doppler echocardiographic examinations of all subjects were performed by the same examiner using a commercially available device (Vivid 7 Pro [equipped with a $2-5 \mathrm{MHz}$ phased-array transducer], GE Healthcare, Horten, Norway). During echocardiography, a single-lead electrocardiogram was recorded continuously.

ASA was detected by transthoracic echocardiography. Patients who had an ASA with a base $>15 \mathrm{~mm}$ and protrusion $>10 \mathrm{~mm}$ were entered into the study. M-mode measurements were performed according to the criteria of the American Society of Echocardiography., ${ }^{9}$

Right atrial, left atrial, and left ventricular end-systolic and end-diastolic diameters were measured. Left ventricular ejection fraction was estimated using Simpson's rule.

\section{Laboratory analyses}

Fasting blood glucose, serum creatinine, total cholesterol, electrolytes, and thyroid-stimulating hormone levels were recorded. Blood samples were drawn by venipuncture to perform routine blood chemistry.

Total and differential leukocyte counts were measured by an automated hematology analyzer. Absolute cell counts were used in the analyses.

\section{Statistical analyses}

SPSS 16.0 statistical program (IBM Corporation, Armonk, NY, USA) was used for statistical study. All values are given as mean \pm standard deviation. Mean values of continuous variables were compared between groups using the Student's $t$-test or Mann-Whitney $U$ test, according to whether they were normally distributed or not, as tested by the Kolmogorov-Smirnov test. A $P$-value of less than 0.05 was considered significant.

\section{Results}

There were no statistically significant differences between the ASA group and controls in respect of age, sex, left atrial and left ventricular diameters, blood pressure, body mass index, and smoking status (Table 1).

When the inflammatory status of the study population was assessed according to leukocytes, neutrophils, and monocytes, neutrophils and NLR were higher $(P<0.001$, respectively) and lymphocytes were lower $(P<0.001)$ in patients with ASA than the controls. Other hematological parameters, including leukocyte, monocyte, hemoglobin, and platelet counts, were not statistically significantly different between the two groups (Table 2).

\section{Discussion}

In the present study, we have found that NLR is significantly higher in patients with ASA.

ASA is a risk factor for arterial embolism. Potential mechanisms of stroke in patients with ASA include paradoxical embolism from a venous source, direct embolization from thrombi formed within the aneurysm, and the formation of thrombi as a result of atrial arrhythmias. ${ }^{11}$ 
Table I Comparison of clinical and echocardiographic features of atrial septal aneurysm patients and controls

\begin{tabular}{llll}
\hline & $\begin{array}{l}\text { Patients } \\
(\mathbf{N}=\mathbf{4 0})\end{array}$ & $\begin{array}{l}\text { Controls } \\
(\mathbf{N}=\mathbf{3 0})\end{array}$ & P-value \\
\hline Age (years) & $54.4 \pm 16.3$ & $49.8 \pm \mathrm{II} .2$ & $\mathrm{NS}$ \\
Male/female $(\mathrm{n} / \mathrm{n})$ & $15 / 25$ & $12 / 18$ & $\mathrm{NS}$ \\
LA diameter $(\mathrm{mm})$ & $33.5 \pm 3.4$ & $34.2 \pm 3.6$ & $\mathrm{NS}$ \\
LVEDD $(\mathrm{mm})$ & $43.1 \pm 4.1$ & $44.2 \pm 4.9$ & $\mathrm{NS}$ \\
LVESD $(\mathrm{mm})$ & $22.6 \pm 2.7$ & $24.4 \pm 2.2$ & $\mathrm{NS}$ \\
RA diameter $(\mathrm{mm})$ & $33.5 \pm 3.3$ & $32.8 \pm 3.1$ & $\mathrm{NS}$ \\
LVEF $(\%)$ & $64.2 \pm 5.2$ & $64.8 \pm 5.3$ & $\mathrm{NS}$ \\
BSA $\left(\mathrm{m}^{2}\right)$ & $1.9 \pm 0.5$ & $1.8 \pm 0.3$ & $\mathrm{NS}$ \\
SPAP $(\mathrm{mmHg})$ & $28.5 \pm 3.8$ & $25.4 \pm 3.4$ & $\mathrm{NS}$ \\
SBP $(\mathrm{mmHg})$ & $121 \pm 23$ & $122.5 \pm 25$ & $\mathrm{NS}$ \\
DBP $(\mathrm{mmHg})$ & $74.2 \pm \mathrm{II}$ & $80.3 \pm 12$ & $\mathrm{NS}$ \\
BMI $\left(\mathrm{kg} / \mathrm{m}^{2}\right)$ & $25 \pm 3.5$ & $23 \pm 3.1$ & $\mathrm{NS}$ \\
Smoking $(\mathrm{n})$ & 10 & $\mathrm{II}$ & $\mathrm{NS}$ \\
\hline A & &
\end{tabular}

Abbreviations: $\mathrm{BMI}$, body mass index; $\mathrm{BSA}$, body surface area; $\mathrm{DBP}$, diastolic blood pressure; LA, left atrium; LVEDD, left ventricular end-diastolic dimension; LVEF, left ventricular ejection fraction; LVESD, left ventricular end-systolic dimension; $R A$, right atrium; SBP, systolic blood pressure; SPAP, systolic pulmonary artery pressure.

In previously published studies, the incidence of AF in ASA patients ranged from $0 \%$ to $23 \% .{ }^{12}$ Janion and Kurzawski ${ }^{13}$ reported that $\mathrm{P}$-wave dispersion and paroxysmal $\mathrm{AF}$ was more common in ASA patients. In another study, ${ }^{14}$ it was reported that supraventricular arrhythmia and P-wave dispersion were more common in ASA patients than in control subjects.

The relationship between leukocytes and increased cardiovascular risk is well known. Horne et $\mathrm{al}^{15}$ have aimed to determine the predictive ability of total WBC count and its subtypes for risk of death or myocardial infarction, and found that high neutrophil and monocyte counts and low

Table 2 Comparison of biochemical parameters of atrial septal aneurysm patients and controls

\begin{tabular}{|c|c|c|c|}
\hline & $\begin{array}{l}\text { Patients } \\
(\mathrm{N}=40)\end{array}$ & $\begin{array}{l}\text { Controls } \\
(\mathrm{N}=\mathbf{3 0})\end{array}$ & $P$-value \\
\hline Glucose (mg/dL) & $97.1 \pm 13.9$ & $93.3 \pm 13.0$ & NS \\
\hline Creatinine (mg/dL) & $0.7 \pm 0.2$ & $0.8 \pm 0.3$ & NS \\
\hline Total cholesterol (mg/dL) & $195.9 \pm 52$ & $199.2 \pm 56$ & NS \\
\hline Triglyceride (mg/dL) & $124 \pm 26$ & $125 \pm 29$ & NS \\
\hline $\begin{array}{l}\text { Low-density lipoprotein } \\
\text { cholesterol ( } \mathrm{mg} / \mathrm{dL})\end{array}$ & $125.3 \pm 9.5$ & $133.7 \pm 15$ & NS \\
\hline $\begin{array}{l}\text { High-density lipoprotein } \\
\text { cholesterol ( } \mathrm{mg} / \mathrm{dL})\end{array}$ & $45.8 \pm 9.5$ & $44.9 \pm 8.6$ & NS \\
\hline Hemoglobin $(g / d L)$ & $14.2 \pm 2.5$ & $14.3 \pm 2.6$ & NS \\
\hline Platelet count $\left(\times 10^{3}\right)$ & $248.5 \pm 62.1$ & $282.3 \pm 79.2$ & NS \\
\hline Leukocytes, $\mathrm{mm}^{3}$ & $8832 \pm 2238$ & $8225 \pm 2116$ & NS \\
\hline Neutrophils, $\mathrm{mm}^{3}$ & $6318 \pm 2425$ & $4686 \pm|3| 1$ & $<0.001$ \\
\hline Lymphocytes, $\mathrm{mm}^{3}$ & $1862 \pm 625$ & $2911 \pm 837$ & $<0.001$ \\
\hline Monocytes, $\mathrm{mm}^{3}$ & $586 \pm 142$ & $458 \pm 124$ & NS \\
\hline Neutrophil/lymphocyte ratio & $3.4 \pm 1.5$ & $1.6 \pm 0.97$ & $<0.001$ \\
\hline
\end{tabular}

lymphocyte counts as well as high NLR are independently related to increased cardiovascular events. Işık et a ${ }^{16}$ showed an independent relationship between NLR and coronary artery ectasia. Leukocyte subtype and NLR are also indicators of systemic inflammation. ${ }^{17,18}$

Recently, NLR has been proposed as a useful biomarker to predict cardiovascular risk. ${ }^{19,20}$

More recently, Gibson et a ${ }^{21}$ speculated that high NLR has been associated with postoperative AF development in patients who have undergone cardiac surgery. Rienstra et $\mathrm{al}^{22}$ examined the 936 participants in the Framingham Heart Study original cohort and found that an increased WBC count was associated with AF incident during 5 years of follow-up.

However, there are no studies on specific relationships between the inflammatory cells and paroxysmal AF in patients with ASA.

When two groups were compared in our study, neutrophil count and NLR of the patients with ASA were significantly higher than in the control group, and lymphocyte levels of ASA patients were significantly lower than lymphocyte levels of the controls.

In this comprehensive study, we have demonstrated that NLR is significantly higher in ASA patients than in control subjects, and it is thought that this may be related to paroxysmal AF and thromboembolism, which are more common in those patients.

\section{Conclusion}

It was found in our study that there might be an association between ASA and NLR. The measurement of NLR may be used to indicate increased risk of arrhythmia such as AF. The most important restriction of our study was the limited number of patients. Another limitation in the current study was that we assessed leukocytes and subtypes by an automatic cell counter. More specific cell determinations could be performed by a flow cytometer with a cluster of differentiation antigens. The other limitations of our study were that it was not prospective, it did not include AF and stroke patients, and the patients were not followed up for arrhythmias and stroke.

We have shown for the first time that patients with ASA have higher NLR compared with controls. Further studies are required to determine the relationship between NLR and ASA.

\section{Disclosure}

The authors report no conflicts of interest in this work. 


\section{References}

1. Hanley P, Tajik AJ, Hynes JK, et al. Diagnosis and classification of atrial septal aneurysm by two-dimensional echocardiography: report of 80 consecutive cases. J Am Coll Cardiol. 1985;6(6): 1370-1382.

2. Janion M, Kurzawski J, Sielski J, Ciuraszkiewicz K, Sadowski M, Radomska E. Dispersion of $\mathrm{P}$ wave duration and $\mathrm{P}$ wave vector in patients with atrial septal aneurysm. Europace. 2007;9(7):471-474.

3. Rigatelli G, Aggio S, Cardaioli P, et al. Left atrial dysfunction in patients with patent foramen ovale and atrial septal aneurysm: an alternative concurrent mechanism for arterial embolism? JACC Cardiovasc Interv. 2009;2(7):655-662.

4. Demir M, Ozmen G, Keçoğlu S, Gunay T, Melek M. Right and left atrial appendage function in patients with atrial septal aneurysm without patent foramen ovale. Acta Cardiol. 2012;67(4):457-460.

5. Imtiaz F, Shafique K, Mirza SS, Ayoob Z, Vart P, Rao S. Neutrophil lymphocyte ratio as a measure of systemic inflammation in prevalent chronic diseases in Asian population. Int Arch Med. 2012;5(1):2.

6. Folsom AR, Wu KK, Rosamond WD, Sharrett AR, Chambless LE. Prospective study of hemostatic factors and incidence of coronary heart disease: the Atherosclerosis Risk in Communities (ARIC) Study. Circulation. 1997;96:1102-1108.

7. Kocaman SA, Sahinarslan A, Kunak T, et al. The particular interactions of the traditional cardiovascular risk factors with different circulating specific leukocyte subtype counts in blood: an observational study. Anadolu Kardiyol Derg. 2011;11(7):573-581.

8. Moreno PR, Falk E, Palacios IF, Newell JB, Fuster V, Fallon JT. Macrophage infiltration in acute coronary syndromes. Implications for plaque rupture. Circulation. 1994;90:775-778.

9. Schiller NB, Shah PM, Crawford M, et al. Recommendations for quantitation of the left ventricle by two-dimensional echocardiography. American Society of Echocardiography Committee on Standards, Subcommittee on Quantitation of Two-Dimensional Echocardiograms. J Am Soc Echocardiogr. 1989;2(5):358-367.

10. Lang RM, Bierig M, Devereux RB, et al. American Society of Echocardiography's Nomenclature and Standards Committee, Task Force on Chamber Quantification, American College of Cardiology Echocardiography Committee, American Heart Association, European Association of Echocardiography, European Society of Cardiology. Task Force on Chamber Quantification: recommendations for chamber quantification. Eur J Echocardiogr. 2006;(2):79-108.
11. Mas JL, Arquizan C, Lamy C, et al; Patent Foramen Ovale and Atrial Septal Aneurysm Study Group. Recurrent cerebrovascular events associated with patent foramen ovale, atrial septal aneurysm, or both. N Engl J Med. 2001;345(24):1740-1746.

12. Mügge A, Daniel WG, Angermann C, et al. Atrial septal aneurysm in adult patients. A multicenter study using transthoracic and transesophageal echocardiography. Circulation. 1995;91(11):2785-2792.

13. Janion M, Kurzawski J. Atrial fibrillation in patients with atrial septal aneurysm. Cardiol J. 2007;14(6):580-584.

14. Demir M, Demir C. Assessment of atrial electromechanical coupling characteristics and P-wave dispersion in patients with atrial septal aneurysm. South Med J. 2011;104(6):385-388.

15. Horne BD, Anderson JL, John JM, et al; Intermountain Heart Collaborative Study Group. Which white blood cell subtypes predict increased cardiovascular risk? J Am Coll Cardiol. 2005;45:1638-1643.

16. Işık T, Ayhan E, Uyarel H, et al. Association of neutrophil to lymphocyte ratio with presence of isolated coronary artery ectasia. Turk Kardiyol Dern Ars. 2013;41(2):123-130.

17. Momiyama Y, Kawaguchi A, Kajiwara I, et al. Prognostic value of plasma high-sensitivity C-reactive protein levels in Japanese patients with stable coronary artery disease: the Japan NCVCCollaborative Inflammation Cohort (JNIC) Study. Atherosclerosis. 2009;207(1):272-276.

18. Papa A, Emdin M, Passino C, Michelassi C, Battaglia D, Cocci F. Predictive value of elevated neutrophil-lymphocyte ratio on cardiac mortality in patients with stable coronary artery disease. Clin Chim Acta. 2008;395(1-2):27-31.

19. Tsai JC, Sheu SH, Chiu HC, et al. Association of peripheral total and differential leukocyte counts with metabolic syndrome and risk of ischemic cardiovascular diseases in patients with type 2 diabetes mellitus. Diabetes Metab Res Rev. 2007;23(2):111-118.

20. Gillum RF, Mussolino ME, Madans JH. Counts of neutrophils, lymphocytes, and monocytes, cause-specific mortality and coronary heart disease: the NHANES-I epidemiologic follow-up study. Ann Epidemiol. 2005;15(4):266-271.

21. Gibson PH, Cuthbertson BH, Croal BL, et al. Usefulness of neutrophil/lymphocyte ratio as predictor of new-onset atrial fibrillation after coronary artery bypass grafting. Am J Cardiol. 2010;105:186-191.

22. Rienstra M, Sun JX, Magnani JW, et al. White blood cell count and risk of incident atrial fibrillation (from the Framingham Heart Study). Am J Cardiol. 2012;109:533-537.
Vascular Health and Risk Management

\section{Publish your work in this journal}

Vascular Health and Risk Management is an international, peerreviewed journal of therapeutics and risk management, focusing on concise rapid reporting of clinical studies on the processes involved in the maintenance of vascular health; the monitoring, prevention and treatment of vascular disease and its sequelae; and the involvement of

\section{Dovepress}

metabolic disorders, particularly diabetes. This journal is indexed on PubMed Central and MedLine. The manuscript management system is completely online and includes a very quick and fair peer-review system, which is all easy to use. Visit http://www.dovepress.com/ testimonials.php to read real quotes from published authors. 